\title{
Brain-Based Aspects of Cognitive Learning Approaches in Second Language Learning
}

\author{
Alireza Navid Moghaddam ${ }^{1} \&$ Seyed Mahdi Araghi ${ }^{1}$ \\ ${ }^{1}$ Department of English, Faculty of foreign Languages, Payam e Noor University, Tabriz, Iran \\ Correspondence: Seyed Mahdi Araghi, Department of English, Faculty of foreign Languages, Payam e Noor \\ University, Po Box 19395-3697, Tehran, Iran. E-mail: alinavid82@yahoo.com \& araghism@gmail.com
}

Received: February 3, 2013 Accepted: March 12, 2013 Online Published: April 3, 2013

doi:10.5539/elt.v6n5p55 URL: http://dx.doi.org/10.5539/elt.v6n5p55

\begin{abstract}
Language learning process is one of the complicated behaviors of human beings which has called many scholars and experts 'attention especially after the middle of last century by the advent of cognitive psychology that later on we see its implication to education. Unlike previous thought of schools, cognitive psychology deals with the way in which the human mind controls learning. Although it was great development on the way of understanding the nature of learning, cognitive psychologists were criticized by other approaches that this caused mush evolution in cognitivism. On the other hand by the rapid growth of technology our understanding of brain has increased, therefore we know its functions and structures even while working. Neuroscience and its implications to educational domain has been increasing time to time, it means neuroscience and education never were so close to each other. Meanwhile, Brain-based researchers can confirm many learning theories that introduced during the educational great efforts of cognitive and non-cognitive approaches. This paper argues in favor of application of those approaches to language classrooms utilizing as guarantee some of the main perception from brain-based learning theories.
\end{abstract}

Keywords: language learning theory, cognitive approach, neuroscience, brain-based learning theory

\section{Introduction}

With the evolution of brain imaging technology, we can study intimately the human's brain even while working, thinking, and learning and its association with education domain. Nowadays, some methods, strategies, and even instructions in education domain can be revised and supported by novel science such as neurology, neuropsychology, to name just a few. Unlike previous learning theories, brain-based learning theory as new paradigm believes that learning takes place when two neurons communicate. Brain-Based Learning considers research depend on neural mechanisms that promote the learning process as a way to optimize presentation. Therefore, learning is duo to the structures and functions of the brain, and as long as the brain is not banned from fulfilling of its instinctive processes, learning occurs. However, genetic and environmental factors, and the connections among cells created by an individual's experiences influence learning. Each brain system within the whole brain seems to work collaboratively to provide meaningful learning (Cain \& Cain, 2006). Thus, it can be said that "the brain learns best when it processes cognitive, affective, and psychomotor information simultaneously" (Jensen, 2005, p. 89). "Brain-based learning that is relevant and meaningful to previous mental, emotional, and physical experiences strengthens memory" (Wolfe, 2001, p. 90).

This learning approach, based on physiological and biological studies of the brain, is derived from the brain theories mentioned already and has developed into guiding principles of learning in the 21st century, increasing the effectiveness of learning and teaching. Researchers like Gardner, Jensen, Caine\& Caine, Sousa, etc. advocate this approach, "Brain-based learning is a natural, motivating, and positive way of maximizing learning and teaching." It is an approach that is based on the ways our brain learns best" (Jensen, 2005, p. 12). Caine and Caine (2006) indicate that brain-based learning includes admitting the brain's rules for meaningful learning and adapting teaching with those rules in brain. Moreover, many educators confirm that neuroscience furnishes a biological and physiological foundation for effective teaching trains (Jensen, 2005). Therefore, educators who design curricula, lesson plans, or classroom activities cannot ignore this approach. This study adopts twelve mind / brain learning principles described as its teaching and learning guiding principles. The main brain compatible learning and teaching principles follow: 


\section{The brain is a parallel processor}

2. Learning engages the entire physiology.

3. The search for meaning is innate.

4. The search for meaning occurs through "patterning".

5. Emotions are critical to patterning.

6. The brain processes parts and wholes simultaneously.

7. Learning involves both focused attention and peripheral perception.

8. Learning always involves conscious and unconscious processes.

9. We have at least two different types of memory, a spatial memory system and a set of systems for rote learning.

10. We understand and remember best when facts and skills are embedded in natural, spatial memory.

11. Learning is enhanced by challenge and inhibited by threat.

12. Each brain is unique (Caine \& Caine, 1991, pp. 80-87).

Caine and Caine believe that students learn from their whole experience, with every present event, piece of knowledge, or current behavior that is about to be linked to the past learned or stored information. This means that learners must be overexposed to content with context, submerged in learning, involved in talking, listening, reading, and discovering. Implementation of brain-based teaching and learning findings has been put to use in the classroom for many years.

\subsection{Cognitive Implication to Education}

Cognitive science is the interdisciplinary study of the mind, including psychology, education, and recently neuroscience. The adjective cognitive reach to the noun cognition and is the systematic term for the capacity of processing information, for knowing, or more precisely, the process of being aware, thinking, learning and judging. The term is extracted from the Latin root cognoscere, meaning to become aquatinted with, to know, to control, or to organize. In fact, cognitive psychology is interested in the way by which the human mind thinks and learns. With the advent of cognitive psychology, we have been witness of its considerable influence on language learning and teaching methodology. "In a cognitive approach, the learner is seen as an active participant in the learning process, using various mental strategies in order to sort out the system of the language to be learnt" (Williams \& Burden, 1997, p. 13).

\subsubsection{Attention}

Information processing is one of the first approaches of cognitive psychology that turned linguists, psychologists, and language teachers toward the function of mind and abstract mental processes in teaching. Thus, it is clear that there must be factors impacting the learning process. These are attention, perception, and memory. In this section I will be discussing McLaughlin's Attention-Processing (Information-Processing) model of second language learning (cited in Mitchell \& Myles, 2004, p. 99) with support from brain-based learning insights.

Attention is one area where an information processing approach has claimed costly insights into the workings of the human mind for its advocates. Any experienced teacher knows that some learners have remarkable difficulty in paying attention to their affair that this invariable habit gives negative effect on learning. Due to importance of attention on learners ' learning processes, Klatzky suggests that "attention should be seen as a process of filtering out an overwhelming range of incoming stimuli and selecting out only those ones which are important for further processing" (cited in Williams \& Burden, 1997, p. 15). Another view by Best sees attention as a cognitive source which can be used as a vehicle of concentrating our mental efforts when a learning task is new (cited in Williams \& Burden, 1997, p. 15). Wolfe (2001), a consultant on the educational implications and application of current neuroscience and educational research for teaching and learning, states that the brain is always paying attention to something. She believes that attention is selective, it means when students do not pay attention to what we say they focus on something else. Consequently, there are key components in the filtering process to increase students 'attention time in the classrooms. Novelty, important component, is an innate attention-getter. Human's brain is programmed to pay attention to the unusual. Teacher can take advantages of this fact by imbedding information in a surprising or novel manner. However, a characteristic of novelty that problematizes using it on a daily basis is the brain's tendency toward habituation. If a sight or sound is new and unusual, we initially pay much attention. But if this same sight or sound occurs over and over, the brain normally becomes so accustomed to the stimulus that it ignores it. This is what is known as habituation. 
The intensity of stimuli is another factor affecting attention. Ordinarily, the louder a sound or the brighter a light, the more likely each is to draw attention. The third factor is movement that raises the attention. Wolfe (2001) states that in the classroom they might not prove usefully over time because of habituation. She, furthermore, announces that there are two factors strongly influencing whether the brain initially attends to arriving information and whether this attention will be sustained. Emotion and meaning are factors confirmed by many scholars in educational domain that compensate above mentioned three components in filtering process. Subsequently, emotion will be elaborating and later meaning will be discussed.

\subsubsection{Emotion}

Goleman (1995) unlike educational history, critics have dismissed the role of emotions in learning, claims that the emotional mind is far faster than the rational mind (e.g. EQ than IQ). In addition he puts EQ at the highest level of a hierarchy of human abilities such as different types of intelligences. On the other extreme Rogers affirmed, "mainstream educational institutions have focused so intently on the cognitive and have limited themselves so completely to 'educating from the neck up' that this narrowness is resulting in serious social consequences" (cited in Arnold \& Fonseca, 2004 p. 121). Roger's Client Centered Therapy (Brown, 2000) has had an important influence on our existent understanding of learning, even learning in an ELTeducational or pedagogical context. By means of nineteen principles he analyzed human's behavior including learning. "Roger studied the Whole Person as a physical and cognitive, but primarily emotional, being" (cited in Brown, $2000 \mathrm{p}$. 89). He suggest that "this kind of learning best takes place in an atmosphere of unconditional positive regard and can be established when teachers come to see their learners as clients with specific needs to be met" (cited in Williams \& Burden, 1997 p. 35). Then, what needed is for teachers to be facilitators of learning rather to be transferor of raw knowledge. He believes that it could not be possible without establishing a non-threatening learning environment and making a warm relationship between learners and educators.

Today's neuroscientists are making new advances in helping us understand why emotion is an important learning variable, and how the affective dimension of learning is the critical interaction among how we feel, act, and think. Mind and emotions are not separate but rather emotions, thinking, and learning are all connected. Why emotion is important? Sylwester (1995) believes that emotion drives attention and attention drives learning. And LeDoux states"Emotions drive attention, create meaning, and have their own memory pathways" (cited in Jensen, 2005, p. 69). He elucidates this fact due to the structure and mechanism of the brain. The brain is biologically designed to serve first information that has strong emotional content. It is also made a schedule to remember this information longer. As we may know from the discussion of the amygdala, the role it plays is to determine the emotional relevance of the incoming stimuli. Conversely, the role of the cortex is to process the incoming stimuli rationally, to place it in context to make sense of it, and to decide on a course of action. It is explained that "the pathway from the thalamus to the amygdala is much shorter than the pathway from the thalamus to the cortex. In fact, the thalamus/amygdala pathway is one synapse long, allowing the amygdala to receive the information approximately a quarter of a second sooner than the cortex" LeDoux (cited in Wolfe, 2001, p. 87). Thus, educators must be aware of the efficient side of the learning by virtue of emotions.

Correspondingly, there is convincing neurobiological encouragement for the importance of affect for learning. Neurobiologist Damasio (cited in Arnold \& Fonseca, 2004, p. 121), using evidence from studies of the brain, asserts that our emotional life is "an integral component of the machinery of reason"; and in his study on a brain-based model of language acquisition, Schumann (cited in Arnold \& Fonseca, 2004, p. 121) explains that "brain stem, limbic and front limbic areas, which comprise the stimulus appraisal system, emotionally modulate cognition such that, in the brain, emotion and cognition are distinguishable but inseparable. Therefore, from a neural perspective, affect is an integral part of cognition". Neuroscience, then, emphasizes to the need of developing a holistic view of the classroom, taking the physical and effective dimensions of learners into account if their cognitive side is to act optimally.

\subsubsection{Memory}

Another area in which information processing can be taken into account is of memory. Studies indicate that memory is not a unitary concept and that different areas of the brain join in the encoding and retrieving tasks. The description and illustration of different sorts of memory and the procedures of the learning process that donate to the stability of memory and later effectiveness of recall have been the concentration of numerous studies. The initial abstract model of memory belongs to Atkinson and Shiffrin. According to this model, the human memory includes a three-stage sequence. Figure 1 indicates them clearly. 
Sensory memory keeps the impressions of sensory information such as visual and/or sound, after the original stimulus has ceased. These impressions are held passingly in the sensory records, which have a large capacity for unprocessed information, but are only able to hold accurate sensory information momentarily. Miller (1956) describes that of all the information that come to the sensory register, a person will focus only on the few chunks or maps of information that seem prominent. He also noted that the common capacity of an individual is about seven such maps and that only these maps move into the short-term memory.

Short-term memory that also called primary or active memory holds a small amount of information. According to Miller (1956), the outmost is about seven maps of information active in mind, which are in a readily available state for a very short period of time. For these maps in temporary save to become long-term memory a process of rehearsal and/or meaningful association is needed.

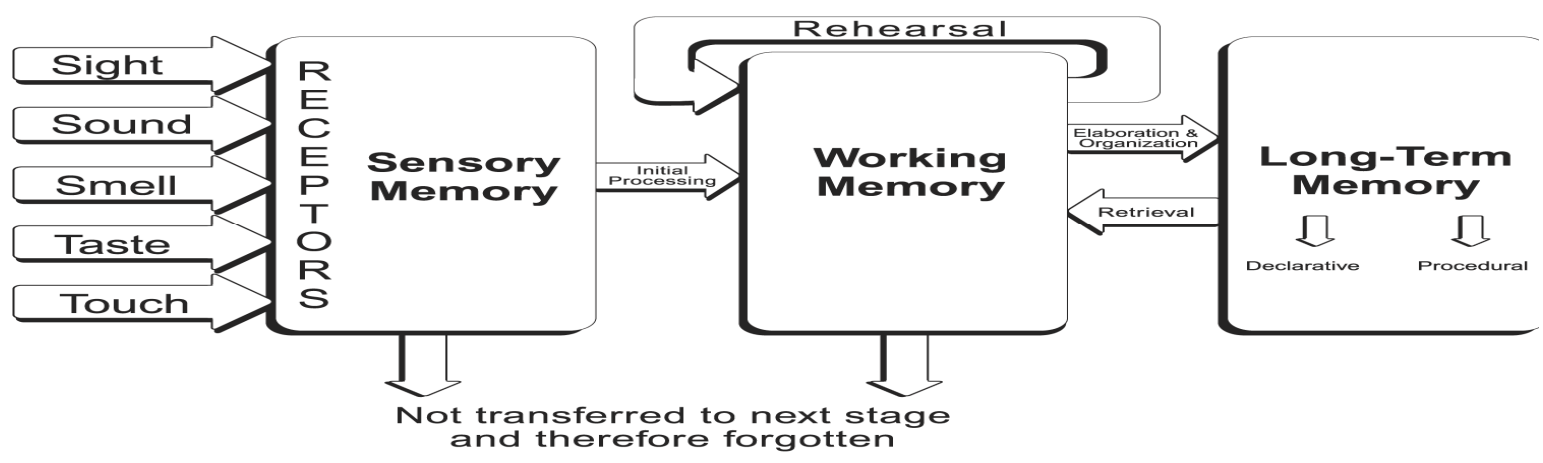

Figure 1. An information processing model of memory

Adapted from Wolfe 2001, Brain matters: Translating Research into Classroom Practice. ASCD Publications, p. 77.

Long-term memory holds information for as little as a few days, or for as long as decades. The information stored is subject to dim in the natural forgetting process. For the information to stay for years, several recalls and retrievals may be needed and/or meaningful association is needed (Miller, 1956).

Due to this fact that people's working memory has limited capacity, which is usually considered to save about seven items at any one time, it is necessary to find ways by which complex material is broken into relevant chunks before sending these to the long-term memory. The most typical way of doing this is by rehearsal. In fact, it may take the simple form of repetition or more detailed tools which involve the connection of meaning to what is about to be remembered. Linkword method was the successful implementation of memory study to foreign language learning (Williams \& Burden, 1997). This technique includes connecting words in both the first and second language to build a picture in the mind. This was the light on upcoming researchers such as Ausubel and his colleagues to state firmly meaningful learning instead of rote learning in the education. Jensen, educational neuropsychologist, problematizes memory and recall in the learning process for very practical reasons. There are three chances to help students in learning (1) The original encoding (2) The maintenance of that memory (3) the retrieval of the learning (Jensen, 2005).

Generally, the latest revelations about the brain provide a powerful structure for understanding and developing memory and recall, and they reveal some good reasons behind the phenomenon of forgetting. Current neuroscience describes memories as dynamic and not fixed (Jensen, 2005). Among the many factors found to be important are background context, date of encoding, emotions, hormones, neurogenesis, and specific signaling stimuli, Nadel and Land (cited in Jensen, 2005, p. 126). Simply, memories are the reasonability of a particular neural firing pattern in a network of cells. Typically, thousands of neurons are activated to retrieve a memory. "More complex memories require the activation of specific networks involving millions of neurons. These networks have varying levels of stability and flexibility depending on the type of encoding and the person's life exposure" (Jensen, 2005, p. 127). This paradigm sees learning as the result of the strengthening of the connection, so optimal recalling requires repetition, rehearsal, and some connected effort at memorization to strengthen the neurons connection (Caine \& Caine, 1991). 
The ways that the brain distributes information can be defined in two major memory pathways of learning (Jensen, 2005). The first is the automatic learning or the implicit learning memory pathway, and the second involves learning by effort or the explicit learning memory pathway (Figure 2). Implicit learning can be subdivided into reflexive or automated non-conscious learning, and into procedural or hands-on physical skills learning. Explicit learning occurs in two initial ways: information inserted in context is saved in the episodic memory, which means that it is connected to a particular episode, and information driven in content is stored in the semantic memory, which means that it is in relation to facts that are usually derived from reading and studying. The difference between the two basic explicit learning pathways has been explained clearly by Jensen (2005, p. 132):

Episodic memory forms quickly, is easily updated, requires no practice, is effortless, and is used naturally by everyone. What did you have for dinner last night? This question triggers your episodic memory. Not only will context cues help you remember the answer, a body movement or posture, particular music, smell, sound, and so on can trigger your memory.

Semantic memory, on the other hand, is usually formed (or attempted to be formed) through rote practice or memorization. It requires rehearsal, is resistant to change, is isolated from context, has strict limits, inherently lacks meaning, and is linked to extrinsic motivation. If I ask you, "Who was the author of the book we read last night?" your semantic memory is being tapped. This memory pathway is more difficult to establish; it is unnatural and requires practice and consistent rehearsal to encode.

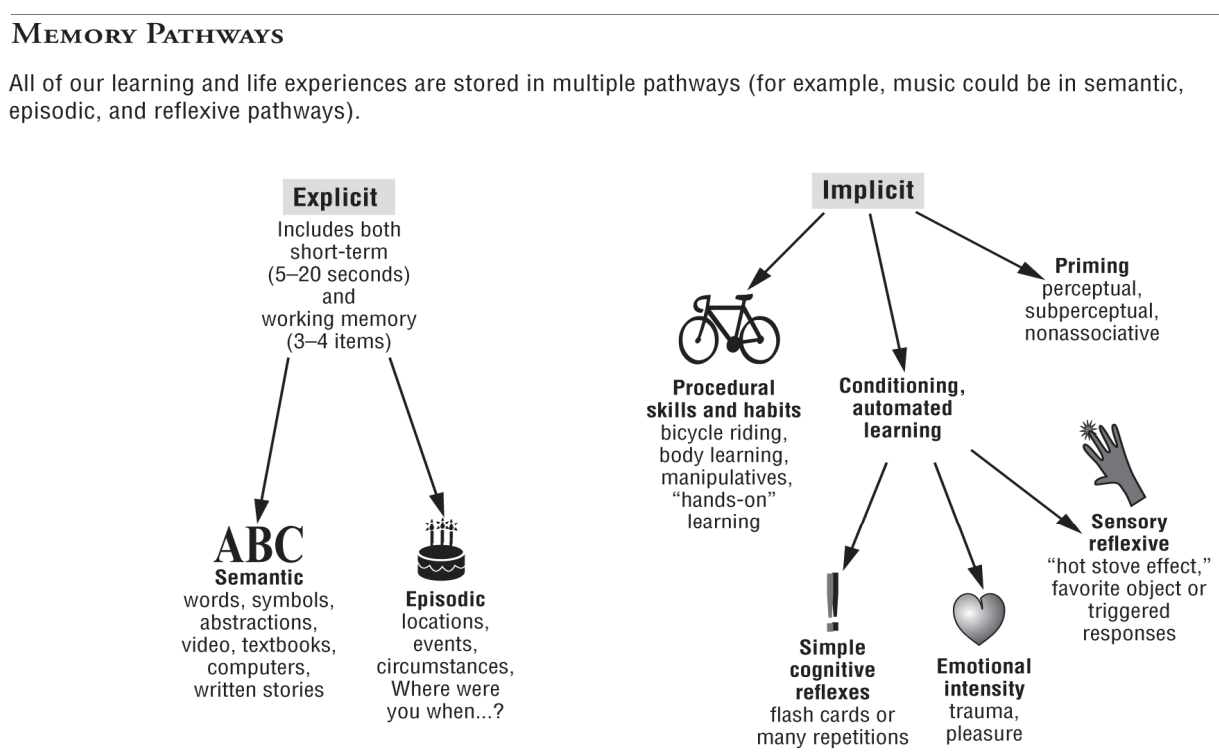

Figure 2. Two major memory pathways to learning

Adapted from Jensen 2005, Teaching with the brain in mind: (2nd ed.). Thousand Oaks, CA: Corwin Press, p. 131.

\subsection{Meaningful Learning}

Another helpful strategy for teachers to assist their students' memorization of information is the application of what the cognitive psychologist Ausubel stated as Advanced Organisers (cited in Williams \& Burden, 1997, p. 17). He has an important role in the history of educational psychology because he stressed the significance of cognitive processes and on the other side he set the concept of meaning at the core of such processes. In fact his Advanced Organizers strategy is to perform as a bridge between previous obtained knowledge and what they are to know. As mentioned before, later on Ausubel and other researchers have attempted to explain the meaningful learning contrasting with rote learning. For him, rote learning includes the mental storage of materials that have little or no connection with existing cognitive structure, on the other hand meaningful learning may be explained as a process of relating and connecting new material to old ones as a hierarchical fashion (Brown, 2000). 
Brown (2000) contents that all learning circumstances can be meaningful providing that (a) learners have a meaningful learning setting that is, a capacity to relate the new learning task to what they already know, and (b) the learning task itself is meaningful for learners. Krashen (1982) was another researcher in Second Language Learning domain who proposed meaningful learning theoretically in the new framework called Input Hypothesis. Although his theory was one of the controversial theories, it could follow its revolutionary path. Krashen's Input hypothesis has taken a bit great attention than his other hypothesizes because of theoretical and practical importance. Particularly, Krashen hypothesizes that when learners understand language at the level of i+1, acquisition would occur. In fact, language or other thing that are being learned must be a bit advanced than previous level of competence. He explained that we move from recent level i to the next level $i+1$. Krashen in his most developed form of hypothesis claims that this novel level must be comprehensible or learning cannot be fulfilled. Later critics were not in opposition with Krashen's, but rather they came to complement his learning (acquisition) hypothesis. Long (1981) moved the research focus towards the ways by which meaning constructs. His Interaction Hypothesis was in the same line with the brain-based principle by Caine and Caine (1991) stating that brain is social brain. In other words, acquisition or learning that is the natural task of brain occurs in exposure to other brains. Long focused on the effects of one type of interaction, negotiation for meaning. It refers to the attempts learners and their conversers make to restructure interaction. Dewey states that people acquire knowledge or learn by processing experiences (cited in Degan, 2011). Thus the active processing of experiences like digesting, thinking about, reflecting on, making sense of experience, and negotiation of meaning is the way to acquire knowledge or to strengthen and internalize information in a way that is both meaningful and conceptually coherent (Caine \& Caine, 1991).

If we want students to use their brains optimally, meaningful learning should highly be taken into account, because meaning is related to depth of information processing. Jensen (2005) describes that meaning comes to mind in many areas of the brain and he distinguishes between reference and sense meaning (surface and deeply felt meaning). He includes relevance, emotional connection, pattern-making and context as leading elements to create a meaningful message. As no interaction is free from context, to memorize any verbal information becomingly, its correspondent context has to be stored as well, and this context needs to interact with the learner's knowledge of the world. It is in the interaction of all these different elements that meaningful learning appears. According to Caine and Caine (1991, p. 47), meaningful learning "refers to storage of items that have so many connections, and are of such quality, that they can be accessed appropriately in unexpected contexts".

\section{Conclusion}

This paper tries to demonstrate the connection between new findings of the brain functions and cognitive approach to the language learning practices. It seems that brain-based research is in the same line with cognitive approach. The findings illustrate that there is great demand for change in the traditional teaching approach, and the interaction between teachers and students. The findings also offer that the most effective approach to teaching and learning is the brain principle by which we learn proposed by Caine and Caine (1991). These findings are presented without intending to deeply in to the description of the neurological complexities of the functioning of the human brain on which they are established. In today's language classroom it is not enough solely to promote linguistic competence or even communicative competence. To create a more brain compatible classroom we must include learning engaging the whole body. Physical activities make the subject to be learned and to be placed in the long term memory, if the lessons involve activities which they can perform, role play, hold, mold, and manipulate clay or other subjects. These will activate the brain parts which will have a long term effect and influence on other parts of the body. This will allow them to store the information in the long-term memory. One last aspect is that after an environment is created and the methods are appropriate in the manner of the brain's learning process, students will not need much instruction, they will be able to understand and do activities on their own.

\section{References}

Arnold, J., \& Fonseca, C. (2004). Multiple Intelligence Theory and Foreign Language Learning: A Brain-based Perspective. IJES, 4(1), 119-136.

Brown, H. D. (2000). Principles of language learning and teaching (4th ed.). NewYork: Longman.

Caine, R., \& N. Caine. (1991). Making connections: Teaching and the human brain. Somerset, NJ: Addison Wesley. PMCid:1669629

Caine, R., \& N. Caine. (2006). Meaningful learning and the executive functions of the brain. The Neuroscience of Adult Learning, 53-62. 
Degan, R. D. (2011). Review of the current knowledge of brain-/mind-based learning to present the optimum climate for, and the guided experience approach to teaching. WORKING PAPER No 73/2011.

Goleman, D. (1995). Emotional intelligence. London: Blumsbury.

Jensen, E. (2005). Teaching with the brain in mind. USA: The Association for Supervision and Curriculum Development.

Krashen, S. (1982). Principles and practice in second language acquisition. Oxford: Pergamon.

Long, M. H. (1981). Input, interaction and second language acquisition. In Winitz, H. (Ed.), Native language and foreign language acquisition. Annals of the New York Academy of Sciences, 379, 259-78.

Mitchell, R., \& Myles, F. (2004). Second language learning theories. Hodder Arnold.

Sylwester, R. (1995). A celebration of neurons: An educator's guide to the human brain. Alexandria, VA: Association for Supervision and Curriculum Development.

Williams, M., \& R. Burden. (1997). Psychology for language teachers. Cambridge: Cambridge University Press. http://dx.doi.org/10.1177/0261927X970163001

Wolfe, P. (2001). Brain matters: Translating research into classroom practice. U. S. A. Association for supervision and Curriculum Development. 